\section{Regulation of Herbal (Traditional) Medicinal Products in the European Union}

\section{Ruiz-Poveda OMP*}

Department of Pharmacology, Faculty of Pharmacy, Universidad Complutense de Madrid, 28040 Madrid, Spain

\begin{abstract}
Legal framework for pharmaceutical legislation in the European Union is complex but clear in its principles, with the main objective of safeguarding public health. The regulation of (traditional) herbal medicinal products is covered by regulations, directives and scientific guidelines to ensure safety and efficacy. Pharmaceutical quality criteria for herbal medicinal products is defined in the amended Directive 2001/83/EC and Directive 2003/63/EC and complemented with several scientific guidelines which ensure that all herbal medicinal products in the European market are manufactured or imported only by authorized manufacturers which have also followed the Good Manufacturing Practices adopted by the Community. This will lead to high quality herbal substances, herbal preparations and herbal medicinal products which can be placed in the market through different types of application: full application, well-established use or traditional use marketing authorization, according to the efficacy data. This article provides an updated review on the specific characteristics of these groups of medicinal products before they are granted a marketing authorization.
\end{abstract}

Keywords: Herbal medicines; Good manufacturing practices; Traditional uses

\section{Abbreviations}

EMA: European Medicines Agency; DER: Drug to Extract Ratio; HMP: Herbal Medicinal Products; THMP: Traditional Herbal Medicinal Products

\section{Introduction}

The European Union (EU) regulatory framework for medicinal products is complex and is based on the need of a marketing authorization before placing medicines in the market. The main objective is to protect public health by assuring quality, efficacy and safety. The requirements and procedures to obtain a marketing authorization are laid down in regulations, directives and scientific guidelines which are contained in the "Rules Governing Medicinal Products in the European Union". Several volumes are included which are supported by other publications with complementary information such as scientific or Good Manufacturing Practice (GMP) guidelines, between others [1].

Medicinal plants have been used since Ancient times in all parts of the world. Nonetheless, regulation of herbal medicines in a legal environment was introduced in the $20^{\text {th }}$ century. The EU regulatory framework includes specific requirements for herbal medicinal products (HMP) which are independent from their legal status: traditional herbal medicinal product (THMP) or products based on clinical evidence - well established use (WEU).

Before a HMP is placed in the market, it must be approved by a MS or by the European Commission by one of the existing types of application: full marketing authorization application, well-established use marketing authorization application or Traditional use marketing registration (Table 1).

The applicant has to submit adequate quality, non-clinical and clinical documentation of the product, irrespectively of the procedure used. Quality requirements of the pharmaceutical product are the same, regardless of the type of application, while efficacy documentation differs between them. The full marketing application is chosen for new medicinal products (new chemical entity) and it has to be completed with the results of pharmaceutical tests (quality documentation), nonclinical (toxicological and pharmacological) studies and clinical trials. Safety data have to be of sufficient size according the existing guidelines; efficacy is demonstrated by results from the clinical trials which have to be in conformity with the guidelines of the corresponding therapeutic area. This type of application is open for HMP, but only a few examples of herbal products have obtained a marketing authorization in the EU in this way.

\section{EU Pharmaceutical Legislation for Herbal Medicinal Products for Human Use}

\section{Quality requirements}

The principles to assure quality of medicinal products are defined mainly in two Directives of volume 1: Directive 2001/83/EC (which was emended by Directive 2004/24/EC) and Directive 2003/63/EC.

The basic legislation lay down in Directive 2001/83/EC describes the general requirements and provides legal definitions of herbal substances, herbal preparations and herbal medicinal products (Table 2). These concepts are essential for setting quality standards for HMP, as they are by definition complex in nature and so quality requirements set for purified compounds are not suitable for herbal products.

According to the Directive 2001/83/EC, monographs in the European Pharmacopoeia (Eur. Ph.) are legally binding and applicable to all substances which are included in it. For substances which do not have a Eur. Ph. monograph, each Member State (MS) may apply its own national pharmacopoeia. Constituents which are not given in any pharmacopoeia shall be described in the form of a monograph under the same headings included in any monograph in the Eur. Ph., i.e., the name of the substance supplemented by any trade or scientific synonyms; the definition of the substance, set down in a form similar to that used in the European Pharmacopoeia; methods of identification

*Corresponding author: Ruiz-Poveda OMP, Department of Pharmacology Faculty of Pharmacy, Universidad Complutense de Madrid, Madrid, Ciudad Universitaria s/n. 28040 Madrid, Spain, Tel: 9139417 67; Fax: 9139417 26; E-mail: olgapalomino@farm.ucm.es

Received April 28, 2015; Accepted June 06, 2015; Published June 13, 2015

Citation: Ruiz-Poveda OMP (2015) Regulation of Herbal (Traditional) Medicinal Products in the European Union. Pharmaceut Reg Affairs 4: 143. doi:10.4172/21677689.1000142

Copyright: (c) 2015 Ruiz-Poveda OMP. This is an open-access article distributed under the terms of the Creative Commons Attribution License, which permits unrestricted use, distribution, and reproduction in any medium, provided the original author and source are credited. 


\begin{tabular}{|c|c|c|}
\hline & Main characteristics & Article $\mathrm{n}^{\circ}$ \\
\hline $\begin{array}{l}\text { Full marketing } \\
\text { authorisation }\end{array}$ & $\begin{array}{l}\text { New medicinal product (new chemical } \\
\text { substance) } \\
\\
\text { Quality documentation } \\
\text { Non-clinical studies } \\
\text { Clinical trials } \\
\text { Efficacy demonstrated by results of clinical trials } \\
\text { Adequate safety data }\end{array}$ & $8(3)$ \\
\hline $\begin{array}{l}\text { Well-established } \\
\text { use }\end{array}$ & $\begin{array}{l}\text { Medicinal products for which there is an } \\
\text { extensive clinical experience } \\
\text { Quality documentation } \\
\text { Substantial clinical experience and scientific data } \\
\text { available, so no new data on clinical trials } \\
\text { No limitation for therapeutic indications }\end{array}$ & $10 \mathrm{a}$ \\
\hline Traditional use & $\begin{array}{l}\text { Products which not fulfill the efficacy } \\
\text { requirements for a marketing authorization = } \\
\text { simplified registration } \\
\text { Efficacy plausible on the bases of long-standing } \\
\text { use and experience } \\
\text { Quality documentation } \\
\text { Therapeutic indications considered to be safe for } \\
\text { use without the supervision of a physician }\end{array}$ & $16 \mathrm{a}$ \\
\hline
\end{tabular}

Table 1: Types of applications for marketing authorization for a HMP in the EU according the Directive 2001/83/EC.

\begin{tabular}{|c|c|}
\hline $\begin{array}{l}\text { Herbal } \\
\text { medicinal } \\
\text { product }\end{array}$ & $\begin{array}{l}\text { Any medicinal product, exclusively containing as active } \\
\text { ingredients one or more herbal substances or one or more } \\
\text { herbal preparations, or one or more such herbal substances in } \\
\text { combination with one or more such herbal preparations. }\end{array}$ \\
\hline $\begin{array}{l}\text { Her } \\
\text { sub }\end{array}$ & $\begin{array}{l}\text { All mainly whole, fragmented or cut plants, plant part, algae, } \\
\text { fungi, lichen in an unprocessed,, usually dried, but sometimes } \\
\text { fresh (...). Herbal substances are precisely defined by the planta } \\
\text { part used and the botanical name according to the binomial } \\
\text { system (genus, species, variety and author). }\end{array}$ \\
\hline $\begin{array}{l}\mathrm{H} \\
\mathrm{pr}\end{array}$ & $\begin{array}{l}\text { Preparations obtained by subjecting herbal substances } \\
\text { to treatments such as extraction, distillation, expression, } \\
\text { fractionation, purification, concentration or fermentation. These } \\
\text { include comminuted or powdered herbal substances, tinctures, } \\
\text { extracts, essential oils, expressed juices and processed } \\
\text { exudates. }\end{array}$ \\
\hline
\end{tabular}

Table 2: Definitions applicable to herbal medicinal products (Directive 2001/83/EC).

and purity tests.

Moreover, all medicinal products have to be manufactured according to the principles and guidelines of GMP for medicinal products. GMP are applicable to both finished HMP and active substances and, according to Article 46 (f) of Directive 2001/83/EC as amended, marketing authorization holders are required to use as starting materials only active substances which have been manufactured in accordance with the guidelines on the GMP for starting materials as adopted by the Community and distributed in accordance with good distribution practices for active substances.

Additional requirements are found in the Directive 2003/63/EC, as Herbal medicinal products differ substantially from conventional medicinal products in so far as they are intrinsically associated with the very particular notion of herbal substances and herbal preparations. It is therefore appropriate to determine specific requirements in respect of these products with regards to the standardized marketing authorization requirements. Then, detailed information on the herbal medicinal product, herbal substances and herbal preparations has to be included, such as the name, address and responsibility of each herbal substance supplier or description of the plant production process, geographical source or drying and storage conditions. The application dossier of a HMP should include specifications and details of all the analytical methods used for testing herbal substances and herbal preparations, results of batch analyses and analytical validation, together with the justification for the specifications.

Most of the quality requirements for HMP are laid down in soft laws (considered as EU measures such as scientific guidelines) which do not have legal force but provide practical harmonization between the MS and the European Medicines Agency (EMA).

The guideline on quality of HMP/THMP covers the general quality aspects of HMP for human and veterinary use, including THMP for human use (EMA, 2014) and indicates which information has to be included in the application dossier. It provides definitions to be taken in account such as genuine (native) herbal preparations, markers, drug to extract ratio (DER) and specifications. Which is more important, it states that the herbal substance or herbal preparation is considered as the whole active substance. In consequence, the quality control of these products has to include appropriate fingerprint analysis to cover not only the content of markers or constituents with known therapeutic activity but also a wider range of chemical constituents.

\section{Efficacy requirements}

Before a HMP is placed in the market, it must be approved by a MS or by the European Commission by one of the existing types of application: full authorization application, well-established use authorization application or Traditional use registration (Table 3).

The applicant has to submit adequate quality, non-clinical and clinical documentation of the product, irrespectively of the procedure used. Quality requirements of the pharmaceutical product are the same, regardless of the type of application, while efficacy documentation differs between them. The full marketing application is chosen for new medicinal products (new chemical entity) and it has to be completed with the results of pharmaceutical tests (quality documentation), nonclinical (toxicological and pharmacological) studies and clinical trials. Safety data have to be of sufficient size according the existing guidelines; efficacy is demonstrated by results from the clinical trials which have to be in conformity with the guidelines of the corresponding therapeutic area. This type of application is open for HMP, but only a few examples of herbal products have obtained a marketing authorization in the EU in this way.

The well-established medicinal use (WEU) in the EU can be applied to medicinal products for which there exists a wide clinical experience within the EU (not only HMP). The assessment may be based in published controlled clinical trials, non-clinical studies and epidemiological studies. In this type of application, there are no limitations to the therapeutic indication, as this will be derived from the available documentation.

\section{(Traditional) Herbal Medicinal Products}

Under the Traditional use registration for herbal medicinal product (article 16e), there exist some herbal products that not fulfill the efficacy requirements for a marketing authorization but are endorsed with a long tradition of use. In this case, no clinical trials on these products have been conducted and the efficacy is based on the long-standing use and experience. This simplified registration procedure is limited to products which are intended for use without medical supervision, with a specified strength and posology, to be used by oral, external or inhalation ways, and which can demonstrate a period of use equal 


\begin{tabular}{|l|l|}
\hline $\begin{array}{l}\text { Herbal } \\
\text { medicinal } \\
\text { product }\end{array}$ & $\begin{array}{l}\text { Any medicinal product, exclusively containing as active } \\
\text { ingredients one or more herbal substances or one or more } \\
\text { herbal preparations, or one or more such herbal substances in } \\
\text { combination with one or more such herbal preparations. }\end{array}$ \\
\hline $\begin{array}{l}\text { Herbal } \\
\text { substances }\end{array}$ & $\begin{array}{l}\text { All mainly whole, fragmented or cut plants, plant part, algae, } \\
\text { fungi, lichen in an unprocessed,, usually dried, but sometimes } \\
\text { fresh (...). Herbal substances are precisely defined by the planta } \\
\text { part used and the botanical name according to the binomial } \\
\text { system (genus, species, variety and author). }\end{array}$ \\
\hline $\begin{array}{l}\text { Herbal } \\
\text { preparations }\end{array}$ & $\begin{array}{l}\text { Preparations obtained by subjecting herbal substances } \\
\text { to treatments such as extraction, distillation, expression, } \\
\text { fractionation, purification, concentration or fermentation. These } \\
\text { include comminuted or powdered herbal substances, tinctures, } \\
\text { extracts, essential oils, expressed juices and processed } \\
\text { exudates. }\end{array}$ \\
\hline
\end{tabular}

Table 3: Definitions applicable to herbal medicinal products (Directive 2001/83/EC).

or superior to 30 years, including at least 15 years within the EU. In this case, therapeutic indications are limited to those which can be considered safe for use without the supervision of a physician such as minor disorders or symptoms that are benign or self- limiting. In case the applicant should consider another kind of indication, the product must be documented with results of clinical and non-clinical studies, so a full application would be necessary.

Simplified registration of THMP is described in Chapter 2a of Directive 2004/24/EC with three main objectives: a) to protect public health by allowing access to safe and high-quality HMP; b) to allow European citizens the access to medicines of their choice, even those HMP with a long tradition of use and which efficacy hasn't been proved by clinical trials performed according the modern standards; c) to facilitate movement of medicinal products on the European market.

Directive 2004/24/EC has two different dimensions: the evaluation by National Competent Authorities (NCA) of applications submitted by companies at any MS in the EU and at the EMA, and the establishment of advisory scientific opinions on the medicinal use of herbal substances or preparations. The directive on THMP also established a new scientific committee, the Herbal Medicinal Products Committee (HMPC) at the EMA in London, in 2004, to replace the previous Working Party on Herbal Medicinal Products (CPMP) with the following aims: to elaborate Community monographs and List entries for herbal substances/preparations; to publish scientific guidelines useful for the application of European legal framework; to publish its scientific opinion on questions related to herbal medicinal products and coordinate its work with the European Quality group. The HMPC is made up by 33 members, one member (and one alternate) nominated by each MS of the EU and by Iceland and Norway (the EFAEFTA states). Among them, also five experts are included, representing specific fields of expertise as clinical and non-clinical pharmacology, toxicology or pediatrician medicine.

The guidelines and the monographs developed and approved by the HMPC are accepted by both companies and NCAs and are used for TUR and WEU marketing authorizations. This committee plays a key role in the harmonization of the regulation of HMP whereby Community herbal monographs have a fundamental role.

\section{Usage of Community herbal monographs in the EU regulation of traditional HMP}

These documents are established for HMP with regards to bibliographic applications (art. 10 a Directive 2001/83/EC) as well as THPMs. Community monographs reflect the scientific opinion of the HMPC on safety and efficacy data concerning a herbal substance. Any single plant or herbal preparation is assessed individually, according to the available information and includes qualitative and quantitative composition, pharmaceutical form(s), therapeutic indication(s), posology and method of administration, contraindications, special warnings and precautions of use, interactions, use in special population (pregnancy, lactation), effects on ability to drive and use machines, undesirable effects, overdose, pharmacological, pharmacodynamics, pharmacokinetic properties and preclinical safety data.

\section{Community list entry}

In the EU, a community list of herbal substances, preparations and combinations thereof for use in THMPs has been established. This list is based in the proposals form HMPC and is gradually developed. Substances or preparations which are included in the list have the main advantage that applicants do not need to provide evidence on the safe or traditional use for its registration at the NCA in the intended use and indication.

A Public statement for one herbal substance/preparation is published because of safety reasons or lack of data to comply with the conditions in the Directive 2004/24/EC (the assessment work didn't allow a monograph to be published) [2].

Community monographs are published by the EMA while list entries are approved and published by the European Commission because they are endorsed with a wider legal status: list entries are legally binding and NCAs should not request additional data on safety and traditional use.

The establishment of monographs and list entries is based on the assessment of the published scientific data, together with the existing products in the market. Most of the assessment work is developed by the Monograph and List Working Party (MLWP) at the HMPC, which was established in 2006. In this working group, a member is designed as rapporteur and is responsible of drafting a monograph and/or list entry which will be later on considered and approved by the HPC and then, by the EMA. The documents are published on the EMA website: Community monographs have to be taken in account by the MS when assessing the application of any company. Monographs are note legally binding and MS are not obliged to follow the monographs.

More than 100 species are included in the priority list with the following data: a) scientific data being assessed (R-Rapporteur assigned); b) evaluation report in progress and discussion in the MLWP (D- Draft under discussion); c) scientific opinion under public consultation (PDraft Published); d) comments after public consultation period being evaluated (PF- Assessment close to finalization - pre-final); e) final opinion adopted (F- Final opinion adopted).

MLWP is also responsible of developing guidelines related to legal requirements for TU and WEU, as well as evaluating hazards and problems related to HMP. For the latter, coordination is established with the Safety Working Party (SWP) from the Committee for Medicinal Products for Human Use (CHMP).

\section{Community herbal monographs to support HMPC authorization}

A community monograph reflects the scientific opinion from the HMPC in relation to safety and efficacy of one herbal substance/ preparation for medicinal use. AS stated before, a community monograph may be used by a company for a TU or WEU application. That's the reason why monographs are divided in to two columns: Well Established Use and Traditional Use (simplified application) (Figure 1). WEU is based in the existence of safety data of sufficient size and 
Citation: Ruiz-Poveda OMP (2015) Regulation of Herbal (Traditional) Medicinal Products in the European Union. Pharmaceut Reg Affairs 4: 143. doi:10.4172/2167-7689.1000142

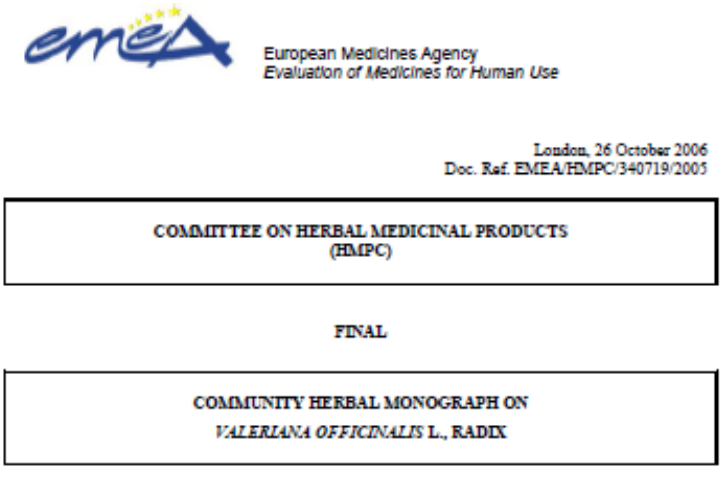

\begin{tabular}{|c|c|}
\hline $\begin{array}{l}\text { DISCUSSTON IN THE DRAFTING GROUP ON SAFETY \& } \\
\text { EFFICACY }\end{array}$ & $\begin{array}{r}\text { May } 2005 \\
\text { Jumo } 2005 \\
\text { Soptumbar } 2005\end{array}$ \\
\hline ADOPTION BY HMPC FOR RELEASE FOR CONSCLTATION & 20 September 2005 \\
\hline END OF CONSULTATION (DEADLINE FOR COMAIENTS) & 31 Jamary 2006 \\
\hline $\begin{array}{l}\text { REDISCUSSION IN WORKTNG PARTY ON COMAINITY } \\
\text { MONOGRAPHS AND COMMISITY LIST }\end{array}$ & $\begin{array}{l}\text { May } 2006 \\
\text { Jaly } 2006\end{array}$ \\
\hline ADOPTION BY HMIPC & 13 July 2006 \\
\hline
\end{tabular}

\begin{tabular}{|c|c|}
\hline KFY & 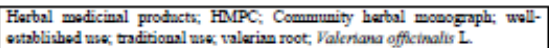 \\
\hline
\end{tabular}

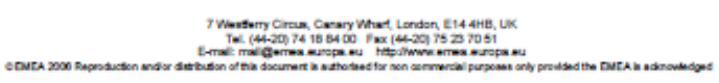

\begin{tabular}{c|}
\hline $\begin{array}{c}\text { COMMTNITY HERBAL MONOGRAPH ON } \\
\text { VALERLANA OFFICINALIS L., RADIX }\end{array}$ \\
\hline
\end{tabular}

1. NAME OF THE Medicinal PRoDUCt

To be specifiod for the individual finishod protact.

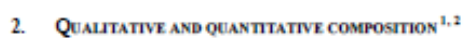

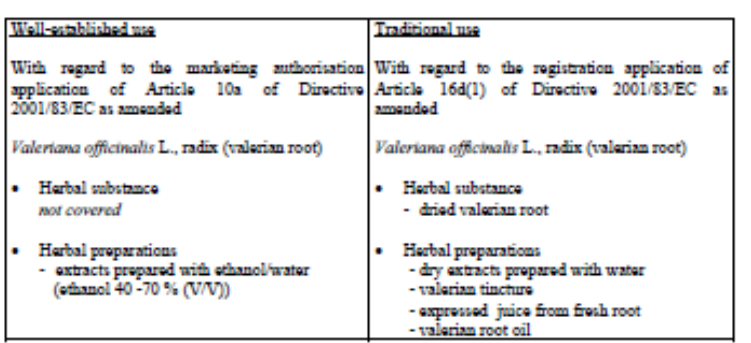

3. Pharmaceutical Form

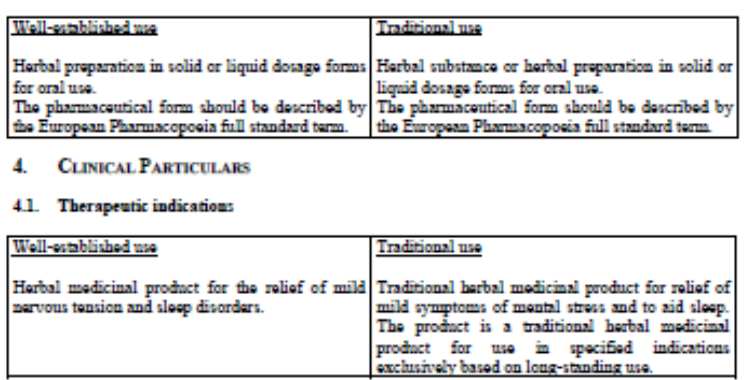

The muterial complies with the Ph. Ear, monographts

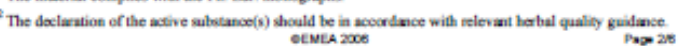

Figure 1: European Community Monograph for Valeriana officinalis L., radix, for WEU and TU.

efficacy data derived from good-quality clinical trials. Traditional use is accepted for those applications which fulfill the criteria shown in the Directive 2004/24/EC.

Each herbal substance/preparation is assessed individually, as the available information may be different for each one. As a result, some substances/preparations may be included in the WEU side, while others will be included in the TU side. If no enough data are available for the substance/preparation, it won't be included in the monograph.

The approved draft art he HMPC is published for public consultation for 3 month at the EMA website. Comments received are discussed and taken in account when necessary to achieve the final version of the monograph which will be finally published at the MA website.

By the end of 2014, 126 monographs have been adopted and published by the EMA: 104 of them for TU only; 9 of the monographs refer only to WEU (Aloe vera, Cimicifuga racemosa, Rhamnus frangula, Plantago ovata - seed and tegumentum-, Plantago afra, Rheum palmatum, Cassia senna - leaves and fruits-.among them 13 monograph include both TU and WEU.

The main application of a community monograph is to serve as a reference material for the marketing application, both for TU or
WEU. Simplified registration is carried on at a national level, so the company gives the dossier to the NCA. With the aim of improving harmonization, the other MSs should recognize the first authorization granted in the first MS, considering that this is based in the European list.

Directive 2004/24/CE established an adaptation period for those herbal products which were on the European market at the moment the Directive was approved. This seven-year period finalized last April $30^{\text {th }}, 2011$ and implies that nowadays those herbal preparations that not fulfill the actual legislation will not be marketed any more.

In the public report form the EMA last June 2014, the status of updating the medicines registration in the EU was shown. The number Traditional use registrations (TUR) and Well-established use marketing authorizations (WEU) grouped for mono component and combination products has increased in the last years (Figure 2).

The European market for HMP is increasing during the last years and even exceeds prescription medicines. The indications approved cover a wide range of therapeutic areas, most of them characteristic of self-medication diseases: the main therapeutic areas are respiratory tract disorders (cough and cold), mental stress and mood disorders, urinary tract and gynecology disorders, sleep disorders and temporary 


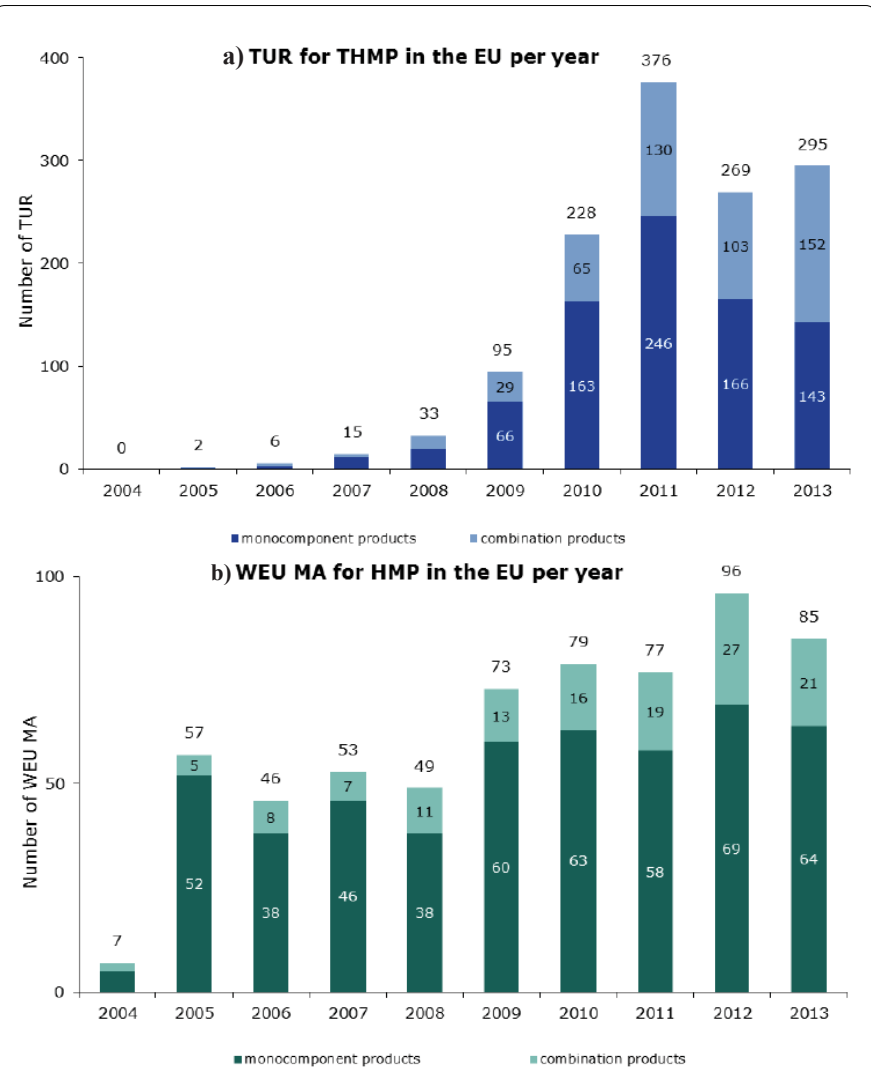

Figure 2: Number of a) Traditional use registrations (TUR) for THMP and b) Well-established use marketing authorizations (WEU) for HMP in the EU grouped by year of authorization for mono component and combination products.

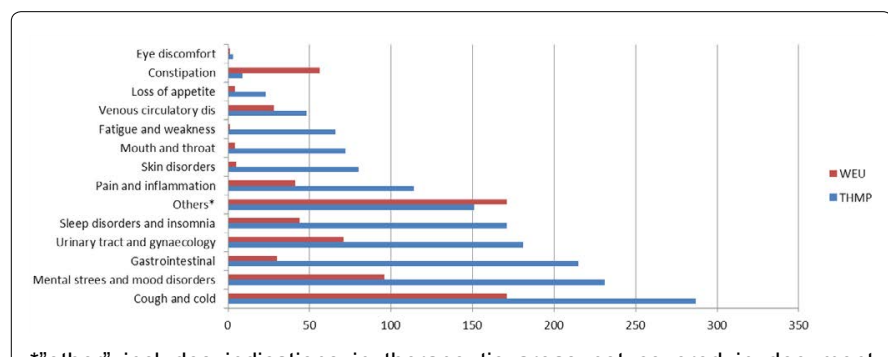

*"other" includes indications in therapeutic areas not covered in document EMA/568620/2009 Rev. 1, such as cardiovascular, improving liver function or peripheral vascular disorders

Figure 3: Number of indications granted in TUR and WEU MA for HMP grouped by typical traditional therapeutic areas in the EU by 31 December 2013. insomnia (Figure 3). Most of the approved THMP until now were updates of existing authorizations and were based on Community monographs. The Summary of Product Characteristics (SoPC) reflects the items in the corresponding monograph [3].

A good correlation between the HMPC work and the evaluation of the dossiers from the companies was detected. The relevance of these documents (as shown by the accepted dossiers) is reflected in the HMPC working plan; as an example, last December 2012, 54 among the 56 species with more than 3 marketing authorizations were listed in the priority list.

\section{Conclusión}

European legal framework for medicinal products does also include herbal medicinal products to assure their quality, efficacy and safety. The specific characteristics of these products led to the development of a simplified procedure to assure pharmaceutical quality, while keeping safety and efficacy criteria according to marketing authorization granted.

Although the starting point was quite different for the MS, nowadays there exist Community monographs for most of the herbal substances/ preparations that are used in the European market and which form the basis for a harmonization scenario. Moreover, HMPC acts as an International Regulatory Body for herbal medicinal products in order to achieve global standards for this type of medicines, according to other International organization such as the International Conference on Harmonization (ICH). The main tasks the HMPC has to face are those related to herbal medicinal products which have been previously marketed abroad the EU and the increasing existence of combination products within the MS.

\section{References}

1. Kroes $\mathrm{BH}$ (2014) The legal framework governing the quality of (traditional) herbal medicinal products in the European Union. J of Ethnopharmacol 158: 449-453.

2. Chinou I (2014) Monographs, list entries, public statements. J of Ethnopharmacol 158: 458-462.

3. Peschel W (2014) The use of community herbal monographs to facilitate registrations and authorisations of herbal medicinal products in the European Union 2004-2012. J of Ethnopharmacol 158: 471-486. 